\title{
Free Scholarly Electronic Journals: What Access Do College and University Libraries Provide?
}

\author{
Michael Fosmire and Elizabeth Young
}

\begin{abstract}
Results of a survey of the level of access provided to selected, free scholarly electronic journals by academic libraries is reported. A list of scholarly journals that are available electronically without any access limitations was compiled, and for each title the number of holding institutions on OCLC and its coverage by major abstracting and indexing services were determined. The twenty-five most popular titles, determined by number of holding institutions on OCLC, were searched on a random sample of library Web sites and catalogs to provide a separate gauge for access levels provided by institutions. Despite approximately half the titles being indexed by major vendors, including 88 percent of the top twenty-five, access levels were fairly low and decreased dramatically with size of the institution. The Bulletin of the American Mathematical Society and Journal of Extension provide examples of free e-journals with print counterparts. Approximately one-half and one-third of the institutions, respectively, provide access to only the print versions of these journals (in the latter case, the print version is no longer produced, so access to current issues is not provided).
\end{abstract}

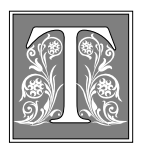

his investigation was sparked by a presentation at the 1999 Special Libraries Association Annual Conference, where a representative from the Institute of Physics stated that "librarians seem to have trouble figuring out what to do with free things." ${ }^{1}$ The statement was in reference to the New Journal of Physics, an electroniconly journal for which there are no subscription fee and no access limitations. The society was wondering why libraries were so slow in cataloging the journal and making it available to their users. Because the New Journal of Physics is a general physics journal published by a reputable source, it would appear to be in the scope of most libraries' collections. However, a quick search on OCLC yielded only a handful of institutions that admitted to holdings of the journal. Although it could be argued that the journal had published only two articles at the time of the conference, the question raised is valid: To what extent are libraries providing appropriate access to free scholarly e-journals?

\section{Background}

There is no doubt that e-journals are here to stay. They offer more convenient navi-

Michael Fosmire is the Physics and Earth and Atmospheric Sciences Librarian at Purdue University; email: fosmire@purdue.edu. Elizabeth Young is the Assistant Coordinator, Technical Services, at SUNY Oswego:e-mail: eyoung@oswego.edu. 
gation between articles, faster time to publishing for authors, and enhanced multimedia content, to name a few advantages. As publishers more fully actualize the e-journal, it soon will be as insufficient to offer only print journals as it is to provide only print abstracts and indexes. Hillary Tomney and Paul F. Burton found that their users had a generally positive attitude toward e-journals, with ease of access (especially from their desktops) being the format's most important perceived advantage. ${ }^{2}$ In addition to the above-listed advantages, 20 to 25 percent also recognized the potential of having attached comments and a broader dissemination of their work.

This study provides one piece of the puzzle of "appropriate" access to free scholarly e-journals- amount of access.

The growth in electronic journals has been dizzying. In 1994, Hans Roes was able to identify thirty-nine peer-reviewed scholarly e-journals. ${ }^{3}$ By 1996, Stephen P. Harter and Hak Joon $\mathrm{Kim}^{4}$ and Steve Hitchcock, Leslie Carr, and Wendy Hall ${ }^{5}$ had found 77 and 115 such titles, respectively. In 1997, ARL's Directory of Electronic Journals, Newsletters, and Academic Discussion Lists (7th edition) claimed 1,002 peerreviewed e-journals. ${ }^{6}$ This growth testifies to the entrenchment of the medium in scholarly publishing.

The overall electronic publishing environment appears to be healthy, with most major publishers now offering electronic versions of their journals, but what about the free electronic journals? Hitchcock, Carr, and Hall found that forty-seven out of eighty-three STM (science, technology, and medicine) titles investigated were free and planned to stay freely accessible. ${ }^{7}$ Looking at all disciplines, Harter and Kim found that almost 90 percent of e-journals were free. ${ }^{8}$ With the increase of commercial publishers in the e-journal market, the numbers have changed considerably, and the current investigation (based on the ARL directory listings) shows that only 213 (18\%) out of 1,209 scholarly e-journals are free.

However, the mere existence of free scholarly e-journals does not automatically mean that libraries should provide access to them. On some level, the journals need to be of good quality and useful. In general, libraries state in their collection development policies that e-journals undergo the same selection process as print journals. ${ }^{9}$ Typically, selection criteria are based on several factors, including: ${ }^{10}$

1. importance of the periodical, as indicated by its inclusion in standard bibliographies and/or "recommended lists";

2. importance of periodical's subject matter in relation to the university's education goals and the curriculum;

3. inclusion of the periodical, and therefore access to its articles, in indexes and abstracts (both print and electronic) maintained by the library;

4. authoritativeness, as reflected by recommendation or adverse criticism by respected authorities;

5. reputation and standing of the publisher;

6. price.

To determine the importance of e-journals, which provides some insight into the fourth factor above, Harter did an impact study. ${ }^{11} \mathrm{He}$ found that of the thirty-eight e-journals that started publication before 1994, twenty-three were cited by other journals indexed in ISI Citation indexes, including seven that were cited more than eleven times. In addition, he found that the Bulletin of the American Mathematical Society was wildly successful, being cited more than 1,500 times in 1994. Public Access Computer Systems Review (PACS-R) ranked in the 71st percentile in impact factor among journals in its subject area, and Psycoloquy achieved a 76th percentile ranking. Thus, some free e-journals have provided high-quality content to their disciplines. Because neither PACS- $R$ nor Psycoloquy were themselves indexed by ISI, their showing was indeed impressive. However, Harter did note that the total number of articles written was rather 
small, so the overall contribution of the journals to the field was less. An impact study of the STM journals from this study's sample found a sizable number of high-quality journals with higher total numbers of articles published. ${ }^{12}$

The third factor listed above was investigated in the present study, which found that 42 percent of the identified free scholarly e-journals were indexed by a major A $+\mathrm{I}$ service (see discussion section). This finding also lends credibility to these publications as a nontrivial part of the scholarly literature. Of course, the sixth factor above is not an issue in the present situation. The reputation and standing of the publisher (factor five) varies considerably by title, with the American Mathematical Society (Bulletin of the American Mathematical Society, Electronic Research Announcements, Notices), Institute of Physics (New Journal of Physics), and the U.S. government (Emerging Infectious Diseases) being examples of highly reputable publishers providing free e-journals. Many of the free ejournals are hosted by professional societies, although certainly many others are hosted simply by a group of interested people working in the same subject area. The other criteria are beyond the scope of the present study, although with the wide variety of subject areas covered by the titles, most libraries would seem to have an interest in some titles (factor two).

Harter's study and the encouraging level of indexing of free scholarly e-journals, along with this study's authors' observations on the other selection factors, provide solid motivation for looking at the level of access libraries provide for their users. This study provides one piece of the puzzle of "appropriate" access to free scholarly e-journals - amount of access. Other research needs to be done to ascertain more fully the quality of the ejournals and thus whether the access reported here is indeed appropriate.

\section{Methods}

Before proceeding with methods used in the study, the term free scholarly electronic journal must be defined because there are certainly ambiguities in each word. For the purposes of this article, free refers to something that can be accessed by anyone with an Internet connection, regardless of a subscription or membership status with any professional society or publisher. Thus, all of the "free, with print" journals do not qualify. The word scholarly refers to the narrow concept of scholarly and peer-reviewed. For example, the very popular and scholarly Issues in Science and Technology Librarianship —although very important to sci-tech librarians, indexed by A\&I services, and free-does not claim to be peerreviewed. ${ }^{13}$ Thus, it was not included in this survey. The criteria for a publication being scholarly, then, are that (1) articles have references and a scholarly treatment and (2) the journal identifies itself as being peer-reviewed. Electronic journal refers not only to electronic-only journals, or even electronic-first journals, but also to any journal that has an electronic version containing at least as much content as the print version and published approximately simultaneously with the print version, if not earlier.

For the purposes of libraries providing access to journals with both print and electronic versions, access is defined as access to the electronic version. Furthermore, the journal must be published currently, so only journals that have published a 1999 issue or have shown other signs of being active were included in this sample. This led, for example, to the exclusion of the Katherine Sharp Review and PACS-R, one of which announced it had ceased publication and the other of which showed no recent activity at the time of this study.

Candidate journals were taken from the Directory of Electronic Journals, Newsletters, and Academic Discussion Lists, 7th edition. A search of peer-reviewed journals in all subject areas yielded 1,209 titles. Inspection of titles in the database to identify free e-journals narrowed the list to 373. Attempts were made to access the remaining e-journals, given the Uniform Resource Locators (URLs) in the directory. The authors assessed whether the journal was (1) 
available from that URL, (2) free, (3) scholarly, and (4) still published. Some of the directory's URLs led to sites with multiple titles, notably the EMIS site, which contains more than twenty e-journals. ${ }^{14}$ The final number of free scholarly e-journals was 213 , much larger than the forty-seven and sixty-seven quoted in the earlier studies. Table 1 contains a breakdown of titles by subject area.

As with any undertaking this large, it is difficult to produce a definitive list of all the free scholarly e-journals. Correct identification depends on the directory having accurate information about the nature of the journal (including its current link) and the journal's Web site having accurate information. Although the authors of this study cannot profess to have compiled a complete list of free scholarly e-journals, they did make every effort to compile as comprehensive a list as possible. This pool of titles includes, at the very least, a large majority of available titles and offers a good indication of the overall nature of the information landscape for this genre of materials.

To gauge the overall level of access academic libraries offer to these titles, two methods were used. First, for all the qualifying titles, OCLC was searched to find the number of holding institutions (see table 2 , column 1). However, it certainly is possible that institutions provide access to a title without registering it with OCLC; thus, a simple search on OCLC may underestimate the total level of access actually provided. Possible reasons for not registering include the cost of formally cataloging a title and responsibility for filling interlibrary loan (ILL) requests. Thus, for example, a journal may be located on an "e-journals" page on the library's Web site but not appear in the catalog.

The second gauge was to look at a sample of institutions' library Web sites and catalogs to determine whether the institution provides access to the title. Because preliminary searching indicated that the overall level of access for free ejournals was low, to maximize the chances of success in finding access, only the top

\begin{tabular}{|lc|}
\hline \multicolumn{2}{|c|}{$\begin{array}{c}\text { TABLE 1 } \\
\text { Breakdown of Free } \\
\text { Scholarly E-journals } \\
\text { by Subject Area }\end{array}$} \\
\hline \hline Subject Area & \% of Sample*(N) \\
\hline Physical sciences & $39(71)$ \\
Math & $28(52)$ \\
Arts and humanities & $22(40)$ \\
Medicine & $21(38)$ \\
Engineering/computers & $12(22)$ \\
Education & $10(18)$ \\
Social sciences & $7(13)$ \\
Biological sciences & $7(12)$ \\
Business & $5(10)$ \\
Library science & $3(5)$ \\
* The percentages add up to more than lon, \\
because interdisciplinary titles were entered \\
under multiple categories. \\
\hline
\end{tabular}

twenty-five journals in terms of number of holding institutions in OCLC were searched.

The institutions surveyed were selected from the list in the Carnegie Foundation's Classification of Institutions of Higher Education..$^{15}$ The universities were selected at random with replacement, so some of the institutions are weighted multiple times in the final analysis. First, the institutions were separated by Carnegie classification type (combining institutions of different levels [I+II]) so that samples of differentsized institutions could be analyzed. Then, a sample size $(\mathrm{N})$ of fifty was chosen for each classification level.

For each institution selected, the library's Web site was located and searches were done in both the online catalog and the rest of the Web site to locate access to the top twenty-five e-journals. If a title was listed in either the catalog or somewhere else on the Web site (typically, an e-journal page), it was considered accessible. Because only the most popular journals were searched, the results of this survey are an overestimation of access provided for free scholarly ejournals as a whole. Title searches for the 
TABLE 2

Top Twenty-five Free Scholarly E-journals by Number of Libraries with Holdings on OCLC

\begin{tabular}{|c|c|c|c|c|c|}
\hline Title & $\begin{array}{c}\text { Number } \\
\text { of Holding } \\
\text { Institutions } \\
\text { on OCLC }\end{array}$ & $\begin{array}{c}\text { \% Research I+II } \\
\text { Institutions } \\
\text { Offering } \\
\text { Access }\end{array}$ & $\begin{array}{c}\text { \% Doctoral I+II } \\
\text { Institutions } \\
\text { Offering } \\
\text { Access }\end{array}$ & $\begin{array}{c}\text { \%Masters I+II } \\
\text { Institutions } \\
\text { Offering } \\
\text { Access }\end{array}$ & Indexed In* \\
\hline Blood, Cells, Molecules, and Diseases & 78 & 52 & 32 & 2 & Medline, WoS, Chem Abs \\
\hline New Journal of Physics & 69 & 66 & 24 & 2 & INSPEC \\
\hline Educause Review & 69 & 14 & 16 & 0 & \\
\hline \multicolumn{6}{|l|}{ Electronic Research Announcements of the } \\
\hline American Mathematical Society & 56 & 50 & 14 & 4 & MathSciNet \\
\hline Emerging Infectious Diseases & 54 & 56 & 34 & 24 & Medline, WoS, GSI \\
\hline Bulletin of the American Mathematical Society & 41 & 64 & 44 & 12 & MathSciNet \\
\hline Psycoloquy & 38 & 34 & 10 & 4 & - \\
\hline Electronic Green Journal & 32 & 28 & 20 & 6 & PAIS, GSI, Env. Abs. \\
\hline Architronic & 28 & 20 & 8 & 0 & Avery \\
\hline Early Modern Literary Studies & 28 & 16 & 16 & 6 & MLA \\
\hline Education Policy Analysis Archives & 28 & 36 & 12 & 2 & ERIC \\
\hline Journal of Seventeenth-Century Music & 28 & 32 & 14 & 2 & - \\
\hline Journal de Théorie des Nombres de Bordeaux & 28 & 14 & 0 & 0 & MathSciNet \\
\hline Music Theory Online & 27 & 20 & 16 & 4 & RILM \\
\hline Conservation Ecology & 25 & 24 & 14 & 6 & Bio Abs, WoS, PAIS \\
\hline Optics Express & 25 & 32 & 4 & 0 & INSPEC, Chem Abs, WoS \\
\hline Geometry and Topology & 24 & 30 & 10 & 0 & MathSciNet \\
\hline Journal of Artificial Intelligence Research (JAIR) & 24 & 16 & 20 & 0 & MathSciNet, WoS \\
\hline Journal of Extension & 24 & 34 & 14 & 0 & Agricola, WoS, ERIC \\
\hline Journal of High-Energy Physics & 23 & 28 & 6 & 0 & MathSciNet, WoS \\
\hline Sociological Research Online & 23 & 18 & 16 & 4 & PAIS \\
\hline
\end{tabular}




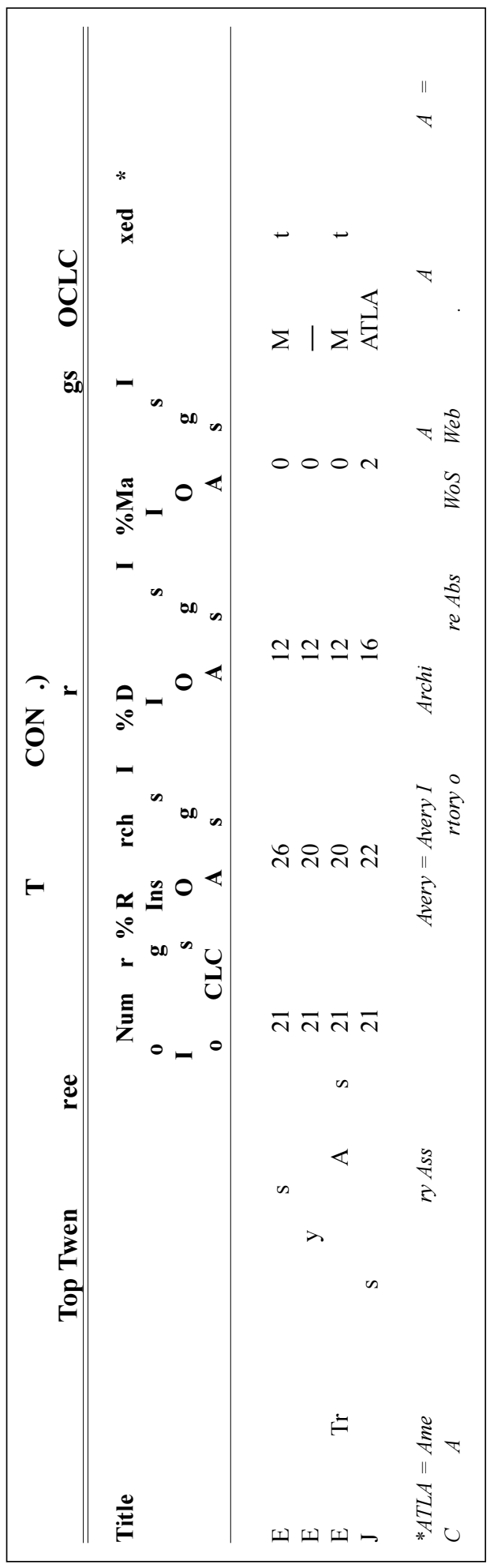

journals on the institutions' Web sites and in catalogs were done in January and February of 2000.

\section{Discussion}

Overall, the number of e-journals that showed holdings in OCLC was rather large. Of the 213 journals investigated, $56(26 \%)$ had no holdings in OCLC , 70 $(33 \%)$ were held by one to five institutions, $36(17 \%)$ by six to ten institutions, and $51(24 \%)$ by more than eleven institutions. Holdings information for the top twenty-five e-journals is given in table 2. Another indicator of the relevance of titles is their inclusion in major indexing and abstracting services. Ninety-five journals were found to be indexed in a major $\mathrm{A}+\mathrm{I}$ service, with MathSciNet indexing the most e-journals at forty-three ( $83 \%$ of the free mathematics e-journals in the study sample are indexed in this service). ${ }^{16}$ Of the top twenty-five journals by OCLC holdings, 88 percent were indexed by a major $\mathrm{A}+\mathrm{I}$ service.

The free scholarly e-journals represent all subject areas (listed in table 1). The sciences, engineering, and medicine comprise more than 60 percent of the titles identified, but the arts and humanities, education, and the social sciences also are well represented. Similarly, the top twenty-five journals cover all the major subject areas, from the STM literature to arts and humanities and the social sciences. Only business is not represented in the top twenty-five list.

The authors' in-depth analysis of the top twenty-five free scholarly e-journals showed that access to journals varies greatly by size of institution (see table 3). Research institutions provide access to roughly twice as many titles as doctoral institutions and nine times as many as master's-level institutions. Although some of this difference may be attributable to differences in the scope of the collections of the institutions due to the broad distribution of subjects covered by the analyzed jour- 
TABLE 3

Average Number, Minimum, and Maximum of the Twenty-Five Free Scholarly E-journals to Which a Library Provided Access

\begin{tabular}{lccc} 
Type of Institution & Average & Minimum* & Maximum \\
\hline Research I+II & 7.7 & $0(4 \%)$ & 23 \\
Doctoral I+II & 4.1 & $0(28 \%)$ & 18 \\
Master's I+II & .82 & $0(56 \%)$ & 6
\end{tabular}

*The percentages in the minimum column refer to institutions that provided access to none of the top twenty-five scholarly e-journals.

scriptions provide access to the online version, despite there being no restrictions on access. In addition, no institution without a print subscription provided access to the online version of the Bulletin. When such a mainstream free e-journal has such a hard time reaching the library community, the low rate of access to the electronic-

nals, it is likely that at least some journals would support the curriculum or research interests of the institutions. Nevertheless, seven times as many doctoral institutions do not provide access to any of the top twenty-five journals, and fourteen times as many master's-level institutions do not provide access to any of those titles as research institutions do.

The Bulletin of the American Mathematical Society provides a striking example of the lack of institutional access to free scholarly e-journals. If an institution has one subscription to a mathematics journal, it is this one. And if the institution has a subscription to the print version, it follows that it also is interested in the online version (which is available free even without a print subscription). Yet, fully 50 percent of the master's-level institutions have subscriptions to the print version, but only 12 percent also provide access to the electronic version (see table 4). Electronic access increases dramatically with institution size, in the ratio of 1:3:1:0:0:3 for research, doctoral, and master's-level institutions, respectively.

Furthermore, the high level of electronic access to the Bulletin is helped by the URL to the online version in the OCLC record for the print product. Several libraries provided access to the online version almost by default by having links in the print record (not all the URLs were linked, even though most of those catalogs had that capability). With that boost to the access rate, it is surprising that only 54 percent of institutions with print sub- only journals is easily understood.

Some of the other journals also had access levels augmented by other than conscious selection decisions. Blood, Cells, Molecules, and Diseases is a title available on IDEAL through Academic Press (and several institutions volunteered that their access was through the IDEAL site and not the free site). ${ }^{17}$ The Institute of Physics is able to include the New Journal of Physics in its site-licensing agreement for its pay periodicals (even then, some institutions that had signed an agreement with IoP for their subscription journals did not provide access to the New Journal of Physics). Emerging Infectious Diseases is a government document put out by the Centers for Disease Control, and links to the online version were often off the government document print record. Thus, of the five journals with the greatest access

\section{TABLE 4 \\ Print versus Electronic Access to the Bulletin of the American Mathematical Society}

\begin{tabular}{lcc}
$\begin{array}{l}\text { Type of } \\
\text { Institution }\end{array}$ & $\begin{array}{c}\text { Electronic } \\
\text { Access (\%) }\end{array}$ & $\begin{array}{c}\text { Print } \\
\text { Access (\%) }\end{array}$ \\
\hline Research I+II & 64 & 92 \\
Doctoral I+II & 44 & 82 \\
Master's I+II & 12 & 50 \\
& \\
Note: Numbers are percentages of institutions \\
that provide access to the electronic version of \\
the publication and those that provide access to \\
the print version.
\end{tabular}


by the institutions sampled, only one, Electronic Research Announcements of the American Mathematical Society, was not artificially high either by bundling with other journals in a package or because of links from its print version.

The Journal of Extension is an example of a print-based title moving to an entirely online publication. In the case of research and doctoral institutions, 50 percent more (nine and three, respectively) could have provided access to the online version if they had just created a link from the print record, which often contained the note: "Continued by online version." Indeed, although no master'slevel institutions provided access to the journal's online version, six percent provided access to the print version. The journal obviously had met the selection criteria for inclusion in the libraries' collections, but when it ceased to be issued in print, the libraries failed to offer access to the electronic version in either their catalogs or Web sites.

Not including the top five, access to the other top free e-journals, most of which are not well connected to professional society or commercial publishers, hovers around 20 percent for research institutions, 12 percent for doctoral institutions, and 2 percent for master's institutions.

\section{Conclusion}

The genre of free scholarly electronic journals embraces all subject areas and appears to be growing steadily, although the level of access that libraries provide is lower than expected. Although almost half of the e-journals in this study's overall sample and 88 percent of the top twenty-five titles are indexed by a major service, almost no master's-level institutions provide access to them. Moreover, even the typical research institution provides access to only about one-third of the top twenty-five titles. The rest of the free scholarly e-journals are even less accessible through academic libraries. In this case, it appears that the indexing services are substantially ahead of the library community in recognizing the importance of these titles in the scholarly information landscape. The Bulletin of the American Mathematical Society and the Journal of Extension are prime examples of journals that libraries are not providing access to at a level commensurate with their apparent value.

Of course, the present study could not investigate all the factors involved in the selection of new periodical titles by academic libraries, but it certainly appears as though several worthy journals are not getting the attention they deserve from the library community. Further study, perhaps a survey of libraries asking how certain titles did not meet selection requirements, may shed light on the low access rates found in this study. One might investigate whether, for example, the free scholarly e-journals are not meeting the selection criteria, the stated factors for selection are not being used, or a different set of selection factors is being applied to such journals. Indeed, are there still technological barriers to providing access to free scholarly e-journals, especially among the smaller institutions?

If libraries are to prevail in the serials crisis that has been prevalent for the past twenty years, librarians need to reward the journals that are trying to provide content at a reasonable price (in this case, free) by at least making them available in library catalogs and/or on library Web sites. The New Journal of Physics notwithstanding, where the Institute of Physics aggressively marketed its free e-journal in order to get libraries to provide access, the authors would have to agree with the institute's representative that, generally, librarians just do not know what to do with free things.

\section{Notes}

1. Jerry Cowhig, comments at the 1999 Physics, Astronomy, Mathematics Vendor Update, 90th Special Libraries Association Annual Conference, Minneapolis. 
2. Hilary Tomney and Paul F. Burton, "Electronic Journals: A Study of Usage and Attitudes among Academics," Journal of Information Science 24.6 (1998): 419-29.

3. Hans Roes, "Electronic Journals: A Survey of the Literature and the Net," Journal of Information Networking 2.3 (1994): 169-86. Also available online at: http://cwis.kub.nl/ dbi/users/ roes/articles/ej_join.htm.

4. Stephen P. Harter and Hak Joon Kim, "Electronic Journals and Scholarly Communication: A Citation and Reference Study," Proceedings of the Midyear Meeting of the American Society for Information Science, San Diego, May 20-22, 1996, 299-315. Also available online at: http:// php.indiana.edu/ harter/harter-asis96midyear.html.

5. Steve Hitchcock, Leslie Carr, and Wendy Hall, A Survey of STM Online Journals 1990-95: The Calm before the Storm. Available online at: http:/ /journals.ecs.soton.ac.uk/survey/survey.html.

6. Mogge, Dru W., ed., Directory of Electronic Journals, Newsletters and Academic Discussion Lists, Foreward. Available online at: http://db.arl.org/foreword.html.

7. Hitchcock, Carr, and Hall, A Survey of STM Online Journals 1990-95.

8. Harter and Kim, "Accessing Electronic Journals and Other E-Publications: An Empirical Study," College \& Research Libraries 57 (Sept. 1996): 440-56.

9. Elizabeth Parang and Laverna Saunders, Electronic Journals in ARL Libraries: Issues and Trends, SPEC Kit \#202 (Washington, D.C.: ARL, 1994). The SPEC Kit includes copies of collection development policies for e-journals from seven major academic institutions. All of those policy statements claimed that selection policies were the same for electronic journals as they were for print journals.

10. Elizabeth Futas, Collection Development Policies and Procedures, 3rd ed. (Phoenix, Ariz:: Oryx, 1995), 306. The quoted passage is the collection development policy for serials at Hawaii Pacific University. All of the institutions in this text had similar selection criteria, with this example being the most succinct.

11. Stephen P. Harter, "Scholarly Communication and Electronic Journals: An Impact Study," Journal of the American Society for Information Science 49, 6 (1998): 507-16.

12. Michael Fosmire and Song Yu, "Free Scholarly Electronic Journals: How Good Are They?," Issues in Science and Technology Librarianship 27 (summer 2000).

13. At the time of this study, ISTL was not peer-reviewed. However, as of the summer 2000 issue, it will have a peer-reviewed section.

14. European Mathematical Information Service, "The Electronic Library of Mathematics: Mathematical Journals." Available online at: http://www.emis.de/journals/index.html.

15. Carnegie Foundation for the Advancement of Teaching, A Classification of Institutions of Higher Education, 1994 Edition. Available online at: http:/ / www.carnegiefoundation.org/Classification/index.htm.

16. To determine which A+I services index these journals, Ulrich's International Periodicals Directory, 38th ed. (New York: Bowker, 2000) was consulted, as were the following indexes: MathSciNet, INSPEC, MLA, SocioFile, PsycInfo, CINAHL, Agricola, Medline, EconLit, Wilson's: Humanities Abstracts, Social Science Abstracts, Business Abstracts, IIMP, PCI, GeoRef, ATLA, Business and Industry Index, Criminal Justice Abstracts, and Web of Science. Not all journals were listed in Ulrich's, nor did Ulrich's necessarily contain all the indexers of a journal.

17. Subsequent to the original submission of this paper, Blood, Cells, Molecules, and Diseases cut off free access to its most recent issues. Full text for the current five years is available through IDEAL only. 